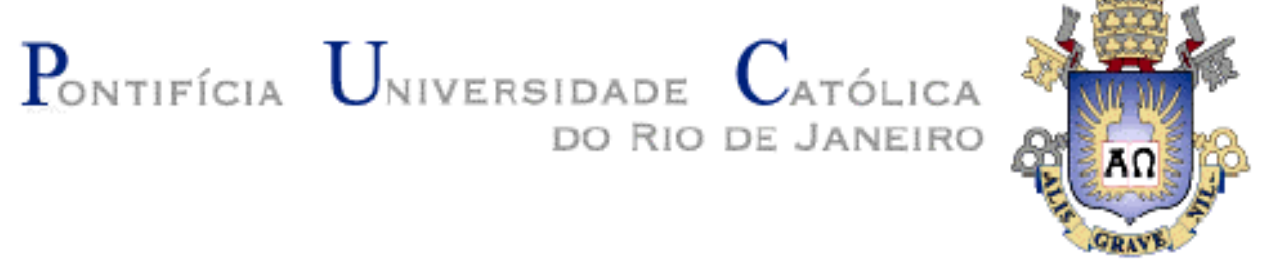

Thaís Rodrigues Gonçalves

Consumo Compensatório de Pessoas

com Baixa Renda

Dissertação de Mestrado

Dissertação apresentada ao Programa de Pósgraduação em Administração de Empresas da PUCRio como requisito parcial para obtenção do título de Mestre em Administração de Empresas.

Orientador: Prof. Luis Fernando Hor-Meyll Alvares

Rio de Janeiro

Abril de 2012 
Thaís Rodrigues Gonçalves

\section{Consumo Compensatório de Pessoas com Baixa Renda}

Dissertação apresentada como requisito parcial para obtenção do grau de Mestre pelo Programa de Pósgraduação em Administração de Empresas da PUC-Rio. Aprovada pela Comissão Examinadora abaixo assinada.

Prof. Luis Fernando Hor-Meyll Alvares

Orientador

Departamento de Administração - PUC-Rio

Prof. Paulo Cesar de Mendonça Motta Departamento de Administração - PUC-Rio

Profa . Mônica Zaidan Gomes

FACC - UFRJ

Profa. Mônica Herz

Vice-Decana de Pós-Graduação do CCS

Rio de Janeiro, 18 de abril de 2012 
Todos os direitos reservados. É proibida a reprodução total ou parcial do trabalho sem autorização da universidade, da autora, e do orientador.

Thaís Rodrigues Gonçalves

Graduou-se em Comunicação Social - Publicidade e Propaganda na UFRJ (Universidade Federal do Rio de Janeiro) em 2008.

Ficha Catalográfica

Gonçalves, Thaís Rodrigues

Consumo compensatório de pessoas com baixa renda / Thaís Rodrigues Gonçalves ; orientador: Luis Fernando Hor-Meyll Alvares. - 2012.

73f. : il. (color.) ; $30 \mathrm{~cm}$

Dissertação (mestrado) - Pontifícia Universidade Católica do Rio de Janeiro, Departamento de Administração, 2012.

Inclui bibliografia

1. Administração - Teses. 2. Valor hedônico. 3. Consumidor de baixa renda. 4. Consumo compensatório. I. Alvares, Luis Fernando Hor-Meyll. II. Pontifícia Universidade Católica do Rio de Janeiro. Departamento de Administração. III. Título.

CDD: 658 
À minha família, por todo carinho, apoio e confiança em minhas realizações. 


\section{Agradecimentos}

Gostaria de expressar minha gratidão a todos àqueles que contribuíram para a concretização deste trabalho, seja através de ensinamentos ou apoio.

À minha mãe, pelo amor incondicional, pelo incentivo constante, pelos ensinamentos e valores carinhosamente divididos ao longo da vida;

Aos meus irmãos, Thiago e Fábio, por me apoiarem em mais esta etapa e por auxiliarem as minhas escolhas servindo de exemplo de direção a seguir;

Ao Felipe, pelo carinho e dedicação, compreendendo os muitos momentos de ausência, apoiando-me quando necessário, oferecendo palavras de conforto em momentos de ansiedade e nervosismo, e comemorado cada uma das minhas vitórias;

Ao Professor Luis Fernando Hor-Meyll, pelos ensinamentos e orientações, que deram direcionamento a este trabalho;

Aos Professores Paulo César Motta e Monica Zaidan Gomes, por participarem da banca, pelo conhecimento e disposição que, certamente, tornarão este trabalho mais rico;

À equipe da área comunitária, principalmente Prof. Helena Guarisco e Vice Reitor Prof. Augusto Sampaio, pelo acesso aos alunos bolsistas e pela imensa disponibilidade em ajudar;

Aos meus amigos, que me motivaram nesta importante etapa, estando ao meu lado, respeitando as ausências e oferecendo ajuda e conforto;

Aos amigos do mestrado, com os quais tive o prazer de conviver ao longo destes dois anos, dividindo aprendizados, descobertas, experiências e alegrias. 


\section{Resumo}

Gonçalves, Thaís Rodrigues; Alvares, Luis Fernando Hor-Meyll. Consumo Compensatório de Pessoas com Baixa Renda. Rio de Janeiro, 2012. 73p. Dissertação de Mestrado - Departamento de Administração, Pontifícia Universidade Católica do Rio de Janeiro.

Famílias de baixa renda representam aproximadamente 53\% da população brasileira e vivenciam situações econômicas e sociais distintas às vivenciadas por classes mais abastadas. Seu comportamento de consumo vem ganhando mais atenção da academia e do meio empresarial. Para examinar como pessoas de diferentes extratos sociais percebem a atividade de compra, atribuindo-lhe maior ou menor valor hedônico, conduziu-se um survey a uma amostra não probabilística, composta por consumidores de baixa e de alta renda. Os resultados encontrados sugerem que há diferença, entre consumidores de baixa e alta renda, quanto ao valor hedônico atribuído à atividade de compra.

\section{Palavras-chave}

Valor hedônico; consumidor de baixa renda; consumo compensatório. 


\section{Abstract}

Gonçalves, Thaís Rodrigues; Alvares, Luis Fernando Hor-Meyll (Advisor). Compensatory Consumption of People with Low Income. Rio de Janeiro, 2012. 73p. Master degree dissertation - Departamento de Administração, Pontifícia Universidade Católica do Rio de Janeiro.

Low income families represent approximately $53 \%$ of the Brazilian population and experience different social and economic situations compared with higher social classes. The consumption behavior of this segment is gaining more attention from academia and in the business environment. In order to examine how different income people assign more or less hedonic value to the shopping activity, a survey was conducted on a non-probabilistic sample of low and high income consumers. Results suggest that there are differences in relation to the hedonic value attributed to shopping activity by low-and high-income consumers.

\section{Keywords}

Hedonic value; low income consumer; compensatory consumption. 


\section{Sumário}

1. Introdução 12

1.1. Objetivo do estudo 15

1.2. Relevância do estudo 15

1.3. Delimitação do estudo 16

1.4. Organização da dissertação 16

2. Revisão de literatura 18

2.1. Consumo compensatório 18

2.2. Consumo por status 19

2.3. Baixo poder e a compensação por consumo de status 21

2.4. Consumo hedônico 22

2.5. Baixa autoestima e a compensação pelo consumo hedônico 24

2.6. Consumidores de baixa renda: características e Comportamentos

2.6.1. Baixa autoestima e baixo poder 26

2.6.2. Consumidores de baixa renda e o consumo aspiracional $\quad 27$

2.6.3. O consumo como fonte de prazer 28

2.7. As hipóteses $\quad 29$

3. Método 30

3.1. Identificação de produtos fortemente relacionados

3.2. Identificação de produtos de natureza predominantemente hedônica (e utilitária) 32

3.3. Verificação de relação entre a condição de baixa renda e
o consumo de status e prazer.

3.4. Limitações do método 38

4. Resultados e discussões $\quad 39$

4.1. Classe de renda $x$ produtos relacionados a status $\quad 40$

4.2. Classe de renda $x$ produtos não relacionados a status 41

4.3. Classe de renda $x$ produtos de dominância hedônica 43

4.4. Classe de renda x produtos de dominância utilitária 44

5. Considerações Finais 46

5.1. Conclusões 46

5.2. Aplicações práticas $\quad 47$

5.3. Sugestões para pesquisas futuras $\quad 48$

6. Referências bibliográficas 49

7. Anexos $\quad 56$

7.1. Anexo A - questionários de pesquisa 56

$\begin{array}{ll}\text { 7.2. Anexo B - Fotografias dos produtos } & 67\end{array}$ 


\section{Lista de tabelas}

Tabela 1 - Correlação entre os itens 31

Tabela 2 - Produtos relacionados (e não relacionados) a status 32

Tabela 3 - Produtos hedônicos ou utilitários - análise fatorial Exploratória

Tabela 4 - Produtos de natureza hedônica (utilitária) 34

Tabela 5 - Distribuição da amostra por idade 39

Tabela 6 - Produtos x status e Prazer $\quad 39$

Tabela 7 - Produtos relacionados a status $\quad 40$

Tabela 8 - Produtos relacionados a status - verificações 41

Tabela 9 - Produtos não relacionados a status 41

Tabela 10 - Produtos não relacionados a status - verificações 42

Tabela 11 - Produtos de dominância hedônica 43

Tabela 12 - Produtos de natureza hedônica - verificações 43

Tabela 13 - Produtos de dominância utilitária 44

Tabela 14 - Produtos de natureza utilitária - verificações 45 


\section{Lista de figuras}

Figura 1 - Pirâmide Econômica Global 13

Figura 2 - Caneta Mont Blanc $\quad 67$

Figura 3 - Automóvel Citroen C4 Pallas 67

Figura 4 - Macbook $\quad 68$

Figura 5 - Bolsa Louis Vuitton 68

Figura 6 - Impressora multifuncional HP 69

Figura 7 - Bloqueador solar Nível $\quad 69$

Figura 8- Caneta BIC $\quad 70$

Figura 9 - Playstation $3 \quad 70$

$\begin{array}{ll}\text { Figura } 10 \text { - Petit gateau } & 71\end{array}$

Figura 11 - Ingresso de cinema $\quad 71$

Figura 12 - Micro-ondas $\quad 72$

Figura 13 - Pilhas $\quad 72$

Figura 14- Aspirina $\quad 73$ 
"O que desejamos determina quem somos e o que vamos fazer deste mundo"

Melinda Davis 